\title{
Patterns of Childhood Cancer Incidence in Saudi Arabia (1999- 2008)
}

\author{
Hind M Al-Mutlaq ${ }^{1}$, Amen Ahmed Bawazir ${ }^{2,3 *}$, Hoda Jradi³, Zeyad Abdulaziz \\ Al-Dhalaan ${ }^{4}$, Ali Al-Shehri ${ }^{3}$
}

\begin{abstract}
Background: Although childhood cancer is a rare disease, 100,000 children younger than 15 years of age die from cancer each year, the majority of them in developing countries. More data need to be gathered and published particularly in developing countries to better understand the scale of the problem. Aims: This study aimed to describe the patterns of childhood cancers in Saudi Arabia over a period of ten years (1999-2008). Materials and Methods: This descriptive retrospective study was based on secondary data from the Saudi Cancer Registry from 1999 to 2008. All Saudi cases (both genders), under the age of 15 years, who were diagnosed with cancer during the study period, were included in this study. Results: Childhood cancer in Saudi Arabia, in the period between 1999 and 2008, accounted for about $8 \%$ of total cancer cases. The most common encountered cancers were leukemia $(34.1 \%)$, followed by lymphoma $(15.2 \%)$, brain $(12.4 \%)$, and kidney cancers $(5.3 \%)$. The overall incidence of childhood cancers increased from 8.8 per 100,000 in 1999 to 9.8 per 100,000 in 2008 . The incidence rates of cancers per 100,000 in the years 1999 and 2008 were generally higher among males, $(9.4$ and 11.5 in males vs. 8.3 and 8.1 in females). The highest incidence rate in the surveyed years was apparent in the birth to age 4 years group. Conclusions: Cancer is an important public health problem in Saudi Arabia and a major ascending contributor to mortality and morbidity in children. More studies are required to describe the patterns of childhood cancers and related risk factors in Saudi Arabia.
\end{abstract}

Keywords: Childhood cancer - Saudi Arabia - epidemiology

Asian Pac J Cancer Prev, 16 (2), 431-435

\section{Introduction}

Childhood cancer is a rare disease. Each year nearly 100,000 children younger than age 15 years die from cancer; the majority of them residing in developing countries with low resources. (Ferlay, Soerjomataram et al., 2013) Low resources countries suffer from lack of facilities for diagnosis of cancers, low access to care at the early stages of diseases, as well as unaffordable treatments. (Terracini, 2011; Sullivan et al., 2013) The causes of childhood cancers are not clearly known. Few cancer conditions can be linked to specific chromosomal and genetic abnormalities, some environmental factors such as ionizing radiation exposure, and consanguinity. (Haroun et al., 2006)

Worldwide, the cancer incidence in children varies from 100 to 180 per 1,000,000 children under 15 years of age (Beatriz et al., 2009). In some developed countries, such as in Ireland, Switzerland, the United State and in Australia the incidence of childhood cancer has reported with rates of $13,13.5,15.3$, and 16 per 100,000 child, respectively, but in Asia the figures are generally lower (CDC 1999-2009; NICR 2005; Michel et al., 2008; Mousavi et al., 2009; Baade et al., 2010; AACR 2012; Wiangnon et al., 2011; Bahoush-Mehdiabadi et al., 2014; Hazarika et al., 2014).

Childhood cancers in the Arab Gulf region affected around 7,673 children in the period extending between 1998 and 2008; which accounted for $8.1 \%$ of total cancer cases during the same period. (GCCCP 2011) In Saudi Arabia, the Saudi Cancer Registery reported around 770 childhood cancer cases in 2008; which represented $6.5 \%$ of the total number of cancer cases in the same year. (SCR 2007) This findings showed more or less similar readings on the percentage of childhood cancer among the total population in the different Arab countries.

The male to female ratio of childhood cancer is generally favorable towards males in some developed countries such as Australia, Canada, and the UK (1.22:1, 1.14:1, and1.12:1; respectively); (Baade et al., 2010; UK 2011; Mitra et al., 2012) which is similar to what has been reported in middle eastern countries such as Egypt, 
Morocco, Jordan, and countries of the Arab Gulf (JCR 2008; NCRPE 2008; GCCCP 2011; Tazi et al., 2013).

According to GLOBOCAN estimation on 2012, leukemia coming in the top of cancers among children diagnosed with malignancy in the globe(Wiemels 2012; Ferlay, Soerjomataram et al., 2013). It is followed by brain and other nervous system malignancies, non-Hodgkin lymphomas, renal tumors and Hodgkin lymphomas. However the rank of each type of cancer is not constant in all countries in the world and remarkable variations in the range of top childhood cancers are clearly noticed from one country to other. (JCR 2008; Jemal et al., 2010; GCCCP, 2011; Mitra et al., 2012).

In most of Arab Countries, including KSA, there is no enough research about the patterns of childhood cancers. This study will show the trends of childhood cancer incidence reported in the Saudi national cancer registry through the period of 1999 to 2008. It will also addressed the most common childhood cancers, and rates of childhood cancers in different regions in the KSA. Findings from this study would probably help the decision makers to plan accordingly required health services.

\section{Materials and Methods}

This descriptive study has conducted using aggregated data from the Saudi Cancer Registry (SCR) in the Kingdom of Saudi Arabia. The SCR is considered as a national cancer registry in the country in Riyadh and established in 1992 under the authority of the Ministry of Health. (SCR 2007) SCR working to collect all data related to cancer registration from all the thirteen administrative regions in the kingdom which include: Riyadh, Estern region, Makkah, Madinah, Qassim, Hail, Jouf, Northen region, Tabouk, Najran, Baha, Asir, and Jezan. Therefore, it covers all the $27,136,977$ million population in the country (2010); 18,707,576 of them are Saudi nationals (Information 2012/1433).

The SCR Main Office indirectly supervises the regional offices and responsible for ensuring the accuracy and quality of data collected in all regions. Quality control processes include verification of site, morphology, and staging information as well as case linkage (tumor and patient), and consolidation of data (SCR 2007).

The data anlayzed in this study were used for the period from 1999 to 2008 (10 years period). These data were underwent a serious of steps to ensure its quality. Usually, in the original sites where regional and hospital cancer registries are located, data were abstracted from patients' medical records, whom already classified as cancer cases based on their clinical diasgnosis, histopathological, and/or radiological diagnosis. Other data (variables) were also collected as related to personal identification (name, ID Number, sex, age), demographic information (address, telephone number, nationality), and tumor details (diagnosis date, primary site, histology, behavior, grade, stage, basis of diagnosis). The primary site and histology of cancers are also identified and coded according to the International Classification of Diseases for Oncology (ICD-O-3), (WHO 2000) and International Classification of Childhood Cancer Groupings (ICCC- grouping) (Steliarova-Foucher et al., 2005). All these data were entered in the computer using a program software called CanReg 4 (IACR) for data analysis and formation of incidence tables and then transformed in to SPSS program (US version 16) for the purpose of further statistical analysis.

All Saudi cancer cases between birth to 14 years of age, of both genders, lived in Saudi Arabia, were re gistered in the SCR in the period between 1999 and 2008, were included in the study as study subjects. However, the study has to exclude any registered cases between 0-14 years of age with missing principle data, such as age, topography, or sex identification.

Data were reviewed for incompletness or missing entries. Staistical analysis included the following: proportions, age specific incidence rates, crude rates, age standrized rates, and $\mathrm{X}^{2}$ calculated and $\mathrm{P}$ value of $(<0.05)$ considered significant in this study. Age Standardization Rate (ASR), is the theoretical rate which the population whould have if it had a standard age structure (Boyle and Parkin, 1991). The crude rate for cancer is the total number of cases registered as aproportion of the total population (Boyle and Parkin, 1991). Cancer incidence rate were also calculated for specific cancers per 100,000 of the population. The incidence rates were calculated based on the mid-point population structure for Saudi population estimated for the population pyramid reported by Central Department of Statistics and Information, Ministry of planning for year 1999 and 2008 (Information 2012/1433). We used the World Standard popualtion in ASR calculation.

\section{Ethical considerations}

No need for informed consent because the used data was secondary data with no linking to patient identity. Data from the Cancer registry were received in special codes and were analyzed and published in special codes without names. The proposal of this study was approved by the research committee in the College of Public Health

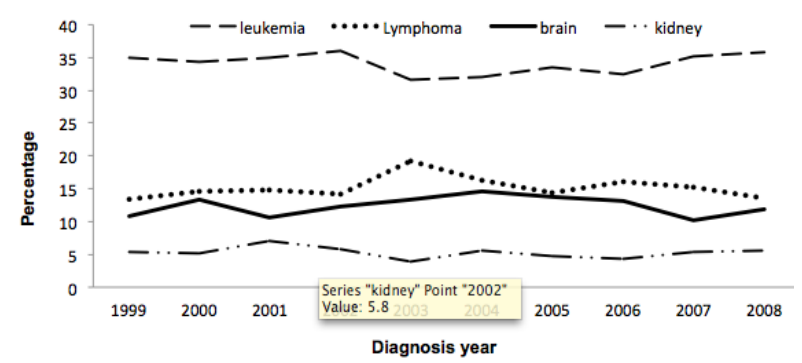

Figure 1. Trend of Common Cancers among Saudi Children (1999-2008)

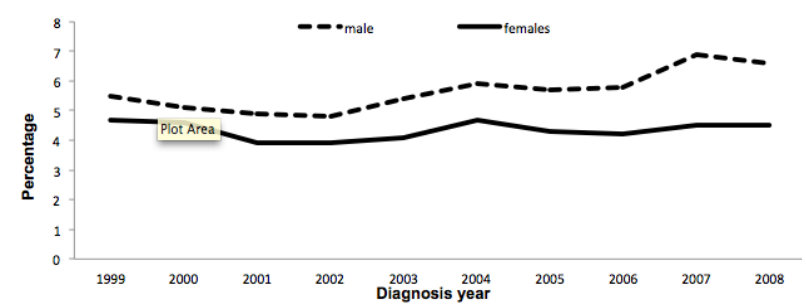

Figure 2. Trend of Childhood Cancer in Both Genders in Saudi Arabia, (1999-2008) 
and Health Informatics at the King Saud Bin Abdulaziz University for Health Sciences as well as the Institutional reseach Board of the King Abdullah Research Centre in the National Guard Health Affair at the Ministry of National Guard, Riyadh, KSA.

\section{Results}

Childhood cancer among Saudi population (1999-2008) In period between 1999 and 2008, childhood cancer ( $<15$ years) has accounted for about $8 \%$ of total cancer cases among all Saudi cancer cases, (5932/74548 cases; unpublished), as seen in Table 1. According to the distribution of the most top cancers in children based on gender, leukemia rates $(34.1 \%)$ found to be almost

Table 1. Childhood Cancers in Saudi Arabia by Years and Gender (1999-2008)

\begin{tabular}{ccccccccc}
\hline \multirow{2}{*}{$\begin{array}{c}\text { Diagnosis } \\
\text { year }\end{array}$} & \multicolumn{2}{c}{ Leukemia } & \multicolumn{2}{c}{ Lymphoma } & \multicolumn{2}{c}{ Brain } & \multicolumn{3}{c}{ Kidney } \\
\hline 1999 & 212 & 35 & 81 & 13.4 & 66 & 10.9 & 32 & 5.3 \\
2000 & 197 & 34.4 & 84 & 14.7 & 76 & 13 & 30 & 5.2 \\
2001 & 182 & 34.9 & 78 & 14.9 & 56 & 10.7 & 37 & 7.1 \\
2002 & 186 & 36 & 73 & 14.1 & 64 & 12.4 & 30 & 5.8 \\
2003 & 178 & 31.5 & 109 & 19.3 & 75 & 13.3 & 22 & 3.9 \\
2004 & 200 & 32 & 102 & 16.3 & 92 & 14.7 & 35 & 5.6 \\
2005 & 200 & 33.4 & 87 & 14.5 & 82 & 13.7 & 29 & 4.8 \\
2006 & 191 & 32.4 & 95 & 16.1 & 78 & 13.2 & 26 & 4.4 \\
2007 & 239 & 35.1 & 104 & 15.3 & 69 & 10.1 & 36 & 5.3 \\
2008 & 236 & 35.9 & 89 & 13.5 & 78 & 11.9 & 37 & 5.6 \\
Total* & 2021 & 34.1 & 902 & 15.2 & 736 & 12.4 & 314 & 5.3 \\
Gender & & & & & & & & \\
Male & 114 & 34.1 & 601 & 17.9 & 427 & 12.7 & 151 & 4.5 \\
Female & 877 & 34 & 301 & 11.7 & 309 & 12 & 163 & 6.3 \\
\hline * calculated from the total childhood cancer cases $(5932)$ & &
\end{tabular}

Table 2. Incidence of Childhood Cancers Per 1,000,000 among Saudi (1999 and 2008)

\begin{tabular}{|c|c|c|c|c|c|c|}
\hline \multicolumn{2}{|c|}{ Age categories } & \multicolumn{2}{|l|}{1999} & \multicolumn{3}{|c|}{2008} \\
\hline (years) & Overall & Male & Female & Overall & Male & Female \\
\hline $0-4$ & 102 & 102 & 102 & 132 & 148 & 115 \\
\hline $5-9$ & 75 & 89 & 61 & 78 & 92 & 63 \\
\hline $10-14$ & 85 & 88 & 82 & 82 & 102 & 62 \\
\hline Total & 88 & 94 & 83 & 98 & 115 & 81 \\
\hline
\end{tabular}

the same in boys and girls over the period of the study. Whereas, lymphoma and brain cancer were higher among boys, (17.9\% and $12.7 \%$ vs. $11.7 \%$ and $12 \%$, respectively). Kidney cancers were higher among girls than boys $(6.3 \%$ and $4.5 \%$, respecively).

The top four cancers reported among Saudi children in this study (1999-2008) were leukemia, lymphomas, brain and nerves tissue cancer, and kidney cancer $(34.1 \%$, $15.2 \%, 12.4 \%, 5.3 \%$, resepectively), as seen in Figure 1 . However variation in the trend were seen based on gender distribution, males were higher in cancer rates than females (Figure 2).

The overall incidence of childhood cancers was increased from 88 per $1,000,000$ in 1999 to 98 per $1,000,000$ in 2008. However, the incidence rates were higher among boys than girls in both years 1999 and 2008, (94 and 115 in boys vs. 83 and 81 in girls/1,000,000). Age group from birth till 4 years had the highest incidence rate in both 1999 and 2008 (Table 2).

Table 3, showed that the highest reported number of cancer patients were from Riyadh followed by Makkah, then Estern Region, Madinah, Asir, Qassim, Tabouk, Jazan, Hail, Jouf, Najran, Baha, and Norther Region. However Riyadh had the highest number of childhood cancers cases (leukemia, lymphoma, brain and kidney cancers), followed by Makkah except for lymphoma estern region had the second highest number of cases.

\section{Discussion}

The occurrence of cancers in Saudi children is low in comparison to other developed countries, but it's an important public health problem as its cause loss of young lives. Saudi Arabia is a young nation with $41.7 \%$ of the popualtion under the age of 15 years, which put a large number of the population at risk of childhood cancer. (SCR 2008; Al Sudairy 2010) Some of these children, constituing almost half of the popualtion, will develop cancer at some point in their lifetime before they reach 15 years of age.

Globally, each year nearly 100,000 children younger than 15 years die from cancer, and the majority of them

Table 3. Distribution of Most Childhood Cancers among Saudi Regions

\begin{tabular}{|c|c|c|c|c|c|c|c|c|c|c|}
\hline Overall & Number & $(\%)$ & Leukemia & $(\%)$ & Lymphoma & $(\%)$ & Brain & $(\%)$ & Kidney & $(\%)$ \\
\hline Riyadh & 1703 & 28.7 & Riyadh & 28.6 & Riyadh & 25.9 & Riyadh & 33.7 & Riyadh & 29.9 \\
\hline Makkah & 1118 & 18.8 & Makkah & 20.1 & Estern region & 16.8 & Makkah & 17.8 & Makkah & 22.0 \\
\hline Estern region & 917 & 15.5 & Eastern region & 15.9 & Makkah & 16.4 & Estern region & 15.7 & Estern region & 13.4 \\
\hline Madinah & 453 & 7.6 & Asir & 7.4 & Madinah & 8.2 & Madinah & 8.5 & Asir & 8.3 \\
\hline Asir & 432 & 7.3 & Madinah & 7.0 & Qassim & 6.5 & Asir & 6.7 & Madinah & 7.6 \\
\hline Qassim & 292 & 4.9 & Qassim & 4.8 & Asir & 6.0 & Qassim & 4.8 & Qassim & 5.1 \\
\hline Tabuk & 219 & 3.7 & Jazan & 3.5 & Tabuk & 4.2 & Tabuk & 3.8 & Tabuk & 3.8 \\
\hline Jazan & 198 & 3.3 & Tabuk & 3.4 & Jazan & 3.8 & Hail & 2.2 & Baha & 2.2 \\
\hline Hail & 149 & 2.5 & Hail & 2.2 & Hail & 3.2 & Najran & 2.0 & North. region & 1.9 \\
\hline Jouf & 122 & 2.1 & Jouf & 1.9 & Jouf & 3.1 & Jouf & 1.9 & Hail & 1.9 \\
\hline Najran & 112 & 1.9 & Baha & 1.8 & Najran & 2.7 & Jazan & 1.9 & Jouf & 1.6 \\
\hline Baha & 104 & 1.8 & Najran & 1.8 & North. Region & 1.8 & North. region & 0.5 & Najran & 1.3 \\
\hline North. region & 84 & 1.4 & North. region & 1.5 & Baha & 1.3 & Baha & 0.4 & Jazan & 1.0 \\
\hline \multicolumn{11}{|c|}{ International/unknown } \\
\hline & 29 & 0.5 & International & 0 & International & 0 & International & 0 & International & 0 \\
\hline Total & 5932 & 100 & Total & 34.1 & Total & 15.2 & Total & 12.4 & Total & 5.3 \\
\hline
\end{tabular}


in developing countries with low resources, as a result of lack of availability of facilities for diagnosis of cancers and access to treatment at early stage as well as unaffordable treatment (Terracini, 2011; Sullivan et al., 2013).

Recently childhood cancers have reached cure rates up to $80 \%$ (Al Sudairy 2010). The promising treatment outcomes of malignancies affecting children makes an examination of the patterns of occurence, age allocation, and geographical distribution of childhood cancers in Saudi Arabia, as presented in this study, a very important step on the childhood cancer research agenda.

In our study we found that an overall incidence of childhood cancers accounted for $8 \%$ of all cancers recorded among Saudis during period between 1999 and 2008 (unpublished). This findings shows similarities with the results reported from the GCC States on cancer incidence for the period 1998-2007 (GCCCP 2011). However, the trend of cancer incidence cases among children in KSA in the period from 1999 up to 2008 has increased from 88 per $1,000,000$ to 98 per $1,000,000$, respectively.

Comparison in incidence rates per $1,000,000$ populations showed remarkable low rates of childhood cancer in Saudi Arabia than other developed countries. For example, childhood cancer incidence was reported with higher rates in UK ( 134 per $1,000,000)$, Germany (163 per 1,000,000) (CR 2010; GCCR 2013). Moreover, it was also reported lower than countries in the Middle east region such as Turkey (143 per 1,000,000), and Algeria (141 per $1,000,000)$, Egypt (138 per $1,000,000)$, and Iraq $(120$ per $1,000,000)$ (Ferlay, Soerjomataram et al., 2013). However, childhood cancer rate in Saudi Arabia found to be higher than the rate in some countries from South Africa and Eastern Asia (Ferlay, Soerjomataram et al., 2013).

Childhood cancer incidence was higher among Saudi boys, with male to female ratio (1.3:1), which is similar to many Arab couneries such Jordan and Tunisia, and the previous report from GCC states (1998-2007) and SCR (2008) (SCR 2008; Al-Tarawneh, Khatib et al., 2010; GCCCP 2011; Missaoui, Khouzemi et al., 2011).

In our study, leukemia was the top childhood cancer as it is the commonest in most industrialized and developing countries. For example many registries in Asian countries such as Indonesia, Thialand, Japan, and Pakistan have reported leukemia as the most frequernt cancer among children which was similar to our findings (Jamal et al., 2006; Sugiyama et al., 2009; Datta et al., 2010; Srina et al., 2010; Missaoui et al., 2011; Wiangnon et al., 2011; Wahidin et al., 2012). However, lymphomas were the second common cancer in our study which resembles the same picture in most developing countries as well as the GCC states (JCR 2008; NCRPE 2008; GCCCP 2011).

Our results showed that Riyadh had the highest number of childhood cancer cases followed by Makkah and Estern region this could be due to presence of tertiary hospitals and cancer centers in these regions that cancer cases reffered to these sites from other regions in country.

In the Arab countries cancer researches face many challenges as reported in the report for an Initiative to Improve Cancer Care in the Arab World these challenges include: concentration of pediatric oncology centers in major regions, lack of public awareness, weak research activities related to pediatric oncology, and lack of national databases (Jazieh, Al Khatib et al., 2010).

Saudi Arabia like other developing countries, went through an economic transition from primarily agricultural activities to more industrial development and manufacturing after the oil boom in the Arabian Gulf (Bener, Ayub et al., 2007). Similar to other developing countries, cancer incidince in KSA increased through out the years because of improvment of health care facilities, their diagnostic capacities, the development of cancer registration practices and possibly the control of commmunicable diseases (Ibrahim et al., 2008; Ferlay, et al., 2010; Jemal et al., 2010). These factors together with the population growing, ageing, adopt western lifestyles contributed to the gradual increase in cancer incidence. (Jemal et al., 2010) The rapid socieconomic changes and lifestyle modifications with an increase in population life expectancy at birth, togather with previously mentioned factors in the country, may have contributed to the documented increase in cancer incidence. (GCCCP, 2011; Terracini, 2011) This increase in the trend of childhood cancer in Saudi Arabia may be a cause of exposure to specific unknown risk factors, so there is need for more researches in the etiology and risk factors of childhood cancer in KSA.

In conclusion, this study provides valuable clues for cancer research where it shows an increament in the trend of cancer in Saudi Arabia throughout the studied years with most common cancer was leukemia and lymphoma, which was higher among boys than girls. However, more epdemiological studies are required to describe the patterns of childhood cancer and the related risk factors in the country to implement adequate cancer control and prevention programs. This type of preventive and cancer care programs should be articulated on primary health care facilities rather than teriary services and should be integrated side by side with other routinely running programs directed to control and prevention of noncommunicable diseases.

\section{Acknowledgements}

The authors would like to thank the people in the Saudi Cancer Registry particularly, Dr. Haya Al-Eid and Dr. Shouki Bazarbashi from SCR and Dr. Ali Al-Zahrani from Gulf Cancer Control Program.

\section{References}

AACR A (2012). Cancer in Australia: an overview 2012. Canberra, AIHW. 74.

Al-Tarawneh M, Khatib S, Arqub K (2010). Cancer incidence in Jordan, 1996-2005. East Mediterr Health J, 16, 837-45.

Al Sudairy R (2010). Cancer prevention and early detection in children malignancies. Pan Arab J Oncol, 3, 79-84.

Baade PD, Youlden DR, Valery PC, et al (2010). Trends in incidence of childhood cancer in Australia, 1983-2006. Br J Cancer, 102, 620-6.

Bahoush-Mehdiabadi G1, Habibi R, Shariftabrizi A, Vossough $P$ (2014). Epidemiologic survey of infantile cancer in Iran based on the data of the largest pediatric cancer referral 
center (Ali- Asghar Children Hospital), 1996-2005. Asian Pac J Cancer Prev, 15, 1211-7.

Beatriz de Camargo, Marceli de Oliveira Santos, et al (2009). Cancer incidence among children and adolescents in Brazil: First report of 14 population-based cancer registries. Int $J$ Cancer, 129.

Bener A, Ayub H, Kakil R, Ibrahim W (2007). Patterns of cancer incidence among the population of Qatar: a worldwide comparative study. Asian Pac J Cancer Prev, 8, 19-24.

Boyle P, Parkin DM (1991). Cancer registration: principles and methods. Statistical methods for registries, IARC Sci Publ, 95, 126-58.

CDC (2013). United states cancer statistics:1999-2009 incidence and mortality web-based report. From www.cdc.gov/uscs.

CR (2010). Childhood Cancer in Great Britain \& UK. from http:// publications.cancerresearchuk.org/downloads/Product/ CS_CS_CHILDHOOD.pdf.

Datta K, Choudhuri M, Guha S, Biswas J (2010). Childhood cancer burden in part of eastern India--population based cancer registry data for kolkata (1997-2004). Asian Pac J Cancer Prev, 11, 1283-8.

Ferlay J, Shin HR, Bray F, Forman D, Mathers C, Parkin DM (2010). Estimates of worldwide burden of cancer in 2008: GLOBOCAN 2008. Int J Cancer, 127, 2893-917.

Gulf Center for Cancer Control \& Prevention (2011). Ten- year cancer incidence among nationals of the GCC states (19982007).

GCCR (2013). Annual Report 2012. 2013, from http://www. kinderkrebsregister.de/fileadmin/kliniken/dkkr/pdf/jb/ jb2012/jb2012_final_s.pdf.

Haroun HM1, Mahfouz MS, Elhaj AM (2006). Patterns of childhood cancer in children admitted to the Institute of Nuclear Medicine, Molecular Biology and Oncology, Wad Medani, Gezira State. J Family Community Med, 13, 71-4.

Hazarika M, Krishnatreya M, Bhuyan C, et al (2014). Overview of childhood cancers at a regional cancer centre in North-East India. Asian Pac J Cancer Prev, 15, 7817-9.

Ibrahim E, Bin SB, Banjar L, Awadalla S, Abomelha MS (2008). Current and future cancer burden in Saudi Arabia: meeting the challenge. Hematol Oncol Stem Cell Ther, 1, 210-5.

Information, C. D. o. s. a. (2012/1433). Central Department of satistics and Information/ Key indicators. Retrieved June 24, , 2012, from http://www.cdsi.gov.sa/.

Jamal S, Mamoon N, Mushtaq S, Luqman M (2006). Pattern of childhood malignancies: study of 922 cases at Armed Forces institute of pathology (AFIP), Rawalpindi, Pakistan. Asian Pac J Cancer Prev, 7, 420-2.

Jazieh A, Al Khatib S, et al (2010). Initiative to Improve Cancer Care in the Arab World Meeting Summary Report Riyadh, KSA, NGHA.

Jordan Cancer Registry (2008). Cancer incidence in Jordan, 2008.

Jemal A, Center MM, DeSantis C, Ward EM (2010). Global patterns of cancer incidence and mortality rates and trends. Cancer Epidemiol Biomarkers Prev, 19, 1893-907.

Jemal A, Siegel R, Xu J, Ward E (2010). Cancer statistics, 2010. CA Cancer J Clin, 60, 277-300.

Michel G, von der Weid NX, Zwahlen M, et al (2008). Incidence of childhood cancer in Switzerland: the Swiss childhood cancer registry. Pediatr Blood Cancer, 50, 46-51.

Missaoui N, Khouzemi M, Landolsi H, et al (2011). Childhood cancer frequency in the center of Tunisia. Asian Pac J Cancer Prev, 12, 537-42.

Mitra D, Shaw AK, Hutchings K (2012). Trends in incidence of childhood cancer in Canada, 1992-2006. Chronic Dis Inj Can, 32, 131-9.

Mousavi SM, Gouya MM, Ramazani R, et al (2009). Cancer incidence and mortality in Iran. Ann Oncol, 20, 556-63.

NCRPE. (2008). National Cancer Registry Program of Egypt (Aswan), 2008. 2013, from http://www.cancerregistry.gov. eg/reports.aspx.

NICR (2005). Cancer in Ireland 1994-2004: A comprehensive report. Ireland, NICR NAtional Cancer Research Institute.

SCR (2007). Cancer incidence survival report- Saudi Arabia 2007. Saudi Arabia, MOH- Saudi Cancer Registry.

SCR (2008). Cancer Incidence Report, Saudi Cancer Registry.

Srina A, Jetsrisuparb A, Komvilaisak P, Kamsaard S, Wiangnon $S$ (2010). Trends in incidence of childhood lymphoma in Khon Kaen, Thailand, 1985-2008. Asian Pac J Cancer Prev, 11, 1683-6.

Steliarova-Foucher, E., C. Stiller, et al (2005). International Classification of Childhood Cancer, third edition. Cancer, 103, 1457-67.

Sugiyama H, Nishi N, Kuwabara M, et al (2009). Incidence and survival of childhood cancer cases diagnosed between 1998 and 2000 in Hiroshima City, Japan. Asian Pac J Cancer Prev, 10, 675-80.

Sullivan R, Kowalczyk JR, Agarwal B, et al (2013). New policies to address the global burden of childhood cancers. Lancet Oncol, 14, 125-135.

Tazi MA, Er-Raki A, Benjaafar N. (2013). Cancer incidence in Rabat, Morocco: 2006-2008. Ecancermedicalscience, 7,338.

Terracini B (2011). Epidemiology of childhood cancer. Environ Health, 10, 8 .

UK C. R. (2011). Cancer stats, Incidence 2008 - UK. 2013, from http://publications.cancerresearchuk.org/downloads/ Product/cs_pdf_incidence_feb_2008.pdf.

Wahidin M, Noviani R, Hermawan S, et al (2012). Populationbased cancer registration in Indonesia. Asian Pac J Cancer Prev, 13, 1709-10.

WHO. (2000, 2000). Classifications/ International Classification of Diseases for Oncology, 3rd Edition (ICD-O-3). Retrieved 19 july, 2012, from http://www.who.int/classifications/icd/ adaptations/oncology/en/index.html.

Wiangnon 1, Veerakul G, Nuchprayoon I, et al (2011). Childhood cancer incidence and survival 2003-2005, Thailand: study from the Thai Pediatric Oncology Group. Asian Pac J Cancer Prev, 12, 2215-20.

Wiemels J (2012). Perspectives on the causes of childhood leukemia. Chem Biol Interact, 196, 59-67. 